\title{
Air Purification Using Mists Generated by an Efficient Multi-fluid Mixer
}

\author{
Michio Sadatomi, Akimaro Kawahara and Yutaro Kawasaki \\ Department of Advanced Mechanical Systems, Graduate School of Science and Engineering, Kumamoto University, Kumamoto \\ 860-8555, Japan
}

Received: July 25, 2016 / Accepted: August 9, 2016 / Published: October 31, 2016.

\begin{abstract}
Sadatomi and Kawahara developed a special twin-fluid atomizer called a multi-fluid mixer, which can spray mists by supplying air alone because water is automatically sucked by a vacuum pressure arisen inside the mixer. In the present paper, firstly, some applications of the mists sprayed by the atomizer are described. Secondly, the performance of the twin-fluid atomizer with best performance was compared with those of the commercial twin-fluid MMA100 type together with the single-fluid swirl type. In the $\mathrm{CO}_{2}$ adsorption tests, mists were sprayed five minutes by the respective types in turn in a test room, and time variations of $\mathrm{CO}_{2}$ concentration in air after the introduction of $\mathrm{CO}_{2}$ in the room were measured at the bottom of the room to compare the $\mathrm{CO}_{2}$ adsorption rates by the mists for the respective cases. In addition, diameters of droplets for the respective types were measured with a microscope. As a result, superiority of our twin-fluid atomizer was confirmed, because $40 \%$ droplets were 20 to $40 \mu \mathrm{m}$ in diameter, and the $\mathrm{CO}_{2}$ adsorption rate by the mists with our twin-fluid atomizer was $25 \%$ higher than that with the commercial ones.
\end{abstract}

Key words: Air purification, mist, atomizers, $\mathrm{CO}_{2}$ adsorption, power.

\section{Introduction}

Atomizing nozzles or atomizers are categorized as single-fluid type, twin-fluid type and special types with rotating disc, vibrating plate, etc. [1]. Of these, the twin-fluid type is usually employed if one must spray a great deal of fine liquid droplets smaller than $100 \mu \mathrm{m}$ [1]. However, the twin-fluid type has a demerit because two pressurizers respectively for water and air must be prepared, and the total cost of equipment and electricity is higher than that for the single-fluid type.

Sadatomi and Kawahara [2] invented a special twin-fluid atomizer called multi-fluid mixer in Fig. 1 which is the twin-fluid type but has a merit because water is automatically sucked through a porous pipe by a negative pressure arisen downstream from the orifice in the mixer. Thus, the mixer can be operated with a lower electric power than the usual twin-fluid type, i.e.,

Corresponding author: Michio Sadatomi, professor, research field: fluids engineering. operable with a solar power [3-8]. The mixer is also usable as a micro bubble generator $[9,10]$ when water is supplied and air is sucked.

In our previous studies, a mathematical model to predict its hydraulic performance was proposed and validated [4], and better geometrical parameters were experimentally clarified [5-8], i.e., the diameter ratio of the orifice to the mixer pipe, the ratio of the outlet length from the porous pipe to the mixer pipe diameter, the geometry of the orifice, the whole size, and the $\mathrm{CO}_{2}$ adsorption performance by the mists.

The purpose of the present study is to compare the above twin-fluid type with commercial single-swirl and twin-fluid types on the spray performance and the $\mathrm{CO}_{2}$ adsorption performance with the mists. In the present paper, firstly, applications of the mists by our twin-fluid atomizer have been described. Secondly, the present experimental results on the hydraulic performance and the $\mathrm{CO}_{2}$ adsorption performance by the mist with the three atomizers have been described. 


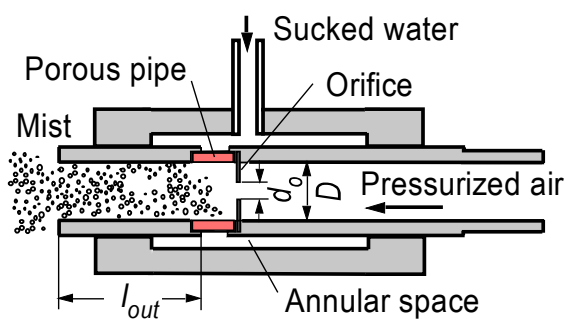

Fig. 1 Twin-fluid atomizer patented by Sadatomi and Kawahara.

\section{Experiment}

\subsection{Test Atomizers}

Three atomizers of $\mathrm{L}, \mathrm{M}$ and $\mathrm{S}$ in our twin-fluid type were tested in order to study the size effects [7]. The pipe and the orifice diameters of $\mathrm{S}$ type were 7 and $4.58 \mathrm{~mm}$ respectively as listed in Table 1 , and the outlet length was $20.5 \mathrm{~mm}$, and the fiber porous pipe was $25 \mu \mathrm{m}$ in porosity and $1.5 \mathrm{~mm}$ in thickness. The $\mathrm{M}$ type and the $\mathrm{L}$ type were twice and three times larger than the $S$ type besides the porosity and the thickness of the porous pipe. Of these, the S type showed the best performance, i.e., the highest in the spray rate to the pneumatic power required [7].

Figs. $2 \mathrm{a}$ and $2 \mathrm{~b}$ show the commercial atomizers tested, i.e., a twin-fluid MMA100 (Kyoritsu Gokin Co., Japan) for atomizing fine mists, and a single-fluid swirl type (Maruhachi Industrials Type Co., Japan) for gardening use. The twin-fluid MMA100 can spray without water power because the air pressure near the atomizer outlet becomes negative. The single-fluid swirl type is composed from a $7 \mathrm{~mm} \mathrm{I}$. D. water inlet, a swirler, and a cap with $0.7 \mathrm{~mm}$ orifice. The inlet diameter is the same as that of the twin-fluid $S$ type.

\subsection{Spray Performance}

Fig. 3 shows the test apparatus for the twin-fluid type atomizer [4-7]. Air was supplied with a compressor

Table 1 Specifications of twin-fluid type atomizers tested.

\begin{tabular}{llll}
\hline Name & $\begin{array}{l}\text { Pipe dia. } D \\
(\mathrm{~mm})\end{array}$ & $\begin{array}{l}\text { Orifice dia. } d_{o} \\
(\mathrm{~mm})\end{array}$ & $\begin{array}{l}\text { Orifice opening area } \\
\text { ratio, }\left(d_{o} / D\right)^{2}\end{array}$ \\
\hline L type & 21 & 13.8 & 0.429 \\
M type & 14 & 9.16 & 0.429 \\
S type & 7 & 4.58 & 0.429 \\
\hline
\end{tabular}

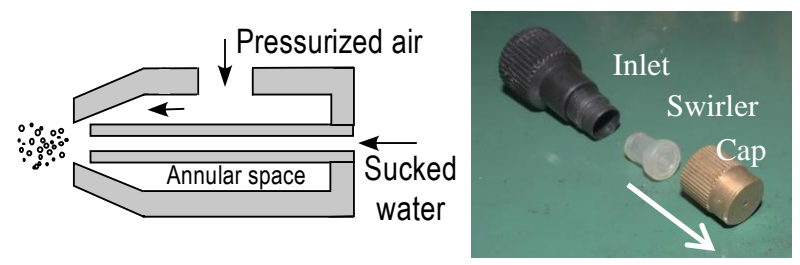

$\begin{array}{ll}\text { (a) Twin-fluid MMA100 } & \text { (b) Single-fluid swirl type }\end{array}$

Fig. 2 Commercial atomizers tested.

after controlling the air volume flow rate, $Q_{G}$. The air flow rate, $Q_{G}$, and the gauge pressure at the atomizer inlet, $P_{G 1}$. The volume flow rate and the pressure were measured with calibrated sensors and a data acquisition system. The accuracies of $Q_{G}$ and $P_{G 1}$ measurements were within $2 \%$ and $1 \%$ from our preliminary tests. The pneumatic power required for the mist spray, $L_{G}$, was obtained by substituting the above measured data into Eq. (1):

$$
L_{G}=\left(P_{G 1}+\rho_{G} v_{G 1}^{2} / 2\right) Q_{G 1} \text {. }
$$

Here, $\rho_{G}$ and $v_{G 1}$ are the air density and the mean air velocity respectively at the atomizer inlet. However, no power was required to supply water, because water was automatically sucked from a water tank whose level was the same as the water inlet of the atomizer. The water supply rate, $Q_{L}$, was measured with a calibrated turbine flow meter within $1 \%$, and could be adjusted by partially closing the flow control valve in the water supply line.

In the single-fluid swirl type test, air supply line and water supply line in Fig. 3 were replaced by a water supply line from a high pressure pump to the atomizer top. The valve in the water line was used to control the volume flow rate, $Q_{L}$, and the gauge pressure at the atomizer inlet, $P_{L 1}$. The hydraulic power needed for the mist spray, $L_{L}$, was obtained by substituting the data into Eq. (2):

$$
L_{L}=\left(P_{L 1}+\rho_{L} v_{L 1}^{2} / 2\right) Q_{L} .
$$

Here, $v_{L 1}$ is the mean water velocities at the atomizer inlet.

Furthermore, mist droplet diameter was measured with an oil pond method. In the method, the droplets were captured momentarily by opening a shutter 


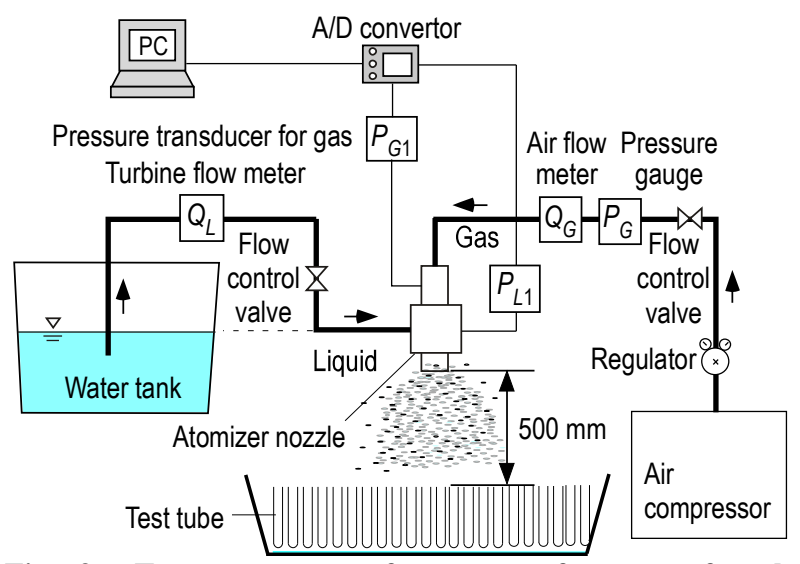

Fig. 3 Test apparatus of spray performance for the twin-fluid type atomizer.

covering the inlet of the oil pond $0.2 \mathrm{~m}$ below the atomizer exit, and the diameters of more than 500 droplets in the pond was measured with a digital micro-scope and an image processing system. Spray angle was measured with a picture and the radial distribution of the mist $0.50 \mathrm{~m}$ below the atomizer exit. The distribution was determined by collecting the droplets with a lot of test tubes square arrayed.

\section{$2.3 \mathrm{CO}_{2}$ Adsorption Performance with Mist}

Figs. $4 \mathrm{a}$ and $4 \mathrm{~b}$ show the test room of $\mathrm{CO}_{2}$ adsorption by the mist, having $2.0 \mathrm{~m}$ in height and 1.2 $\mathrm{m}$ in width and depth. A perforated plate with a cover sheet was placed $1.8 \mathrm{~m}$ above from the bottom, and divided the room into the $\mathrm{CO}_{2}$ room and the mist room. The atomizer was placed at the center of the plate. $\mathrm{CO}_{2}$ concentration in air in the mist room was detected by two sensors placed at the bottom. The procedure of the $\mathrm{CO}_{2}$ adsorption test was as follows: Firstly, $1.5 \mathrm{~L}$ of $\mathrm{CO}_{2}$ at standard condition was filled in a balloon placed outside of the $\mathrm{CO}_{2}$ room. Secondly, the mist was sprayed five minutes in the mist room, three minutes after the spray start the $\mathrm{CO}_{2}$ in the balloon was released to the $\mathrm{CO}_{2}$ room for two minutes for full diffusion. Thirdly, the spray was stopped, and $\mathrm{CO}_{2}$ began to flow down through the perforated plate by removing the cover sheet. At the same time, $\mathrm{CO}_{2}$ concentrations at the bottom of the mist room were measured every 5 seconds for 10 minutes. In order to know the effects of

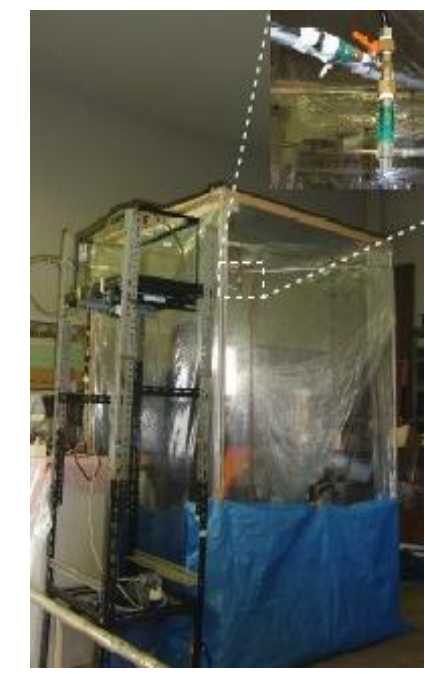

(a) Picture of test room

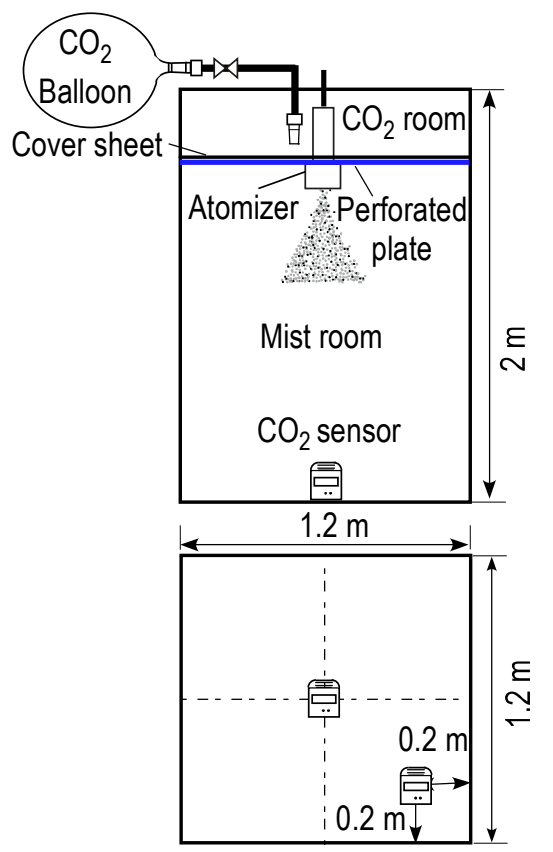

(b) Sketch of apparatus

Fig. 4 Test room for the $\mathrm{CO}_{2}$ adsorption by mists.

the mist spray, a similar measurement with no mist spray was also conducted.

\section{Practical Applications}

Our concern is the development of ecological spray systems which can spray a great deal of finer droplets around $20 \mu \mathrm{m}$ in diameter with a low power such as solar cells. As the practical applications of such a system, an evaporative cooling of fine droplets in greenhouses [3], and baby pig house in summer, and 
adsorptions of smoke and fuel gas emitted from combustors, etc. have already been conducted.

Figs. 5 and 6 show the evaporative cooling of a baby pig house and a solar cell on the roof, which was broadcasted by the Tokyo Broadcasting System Television. In the cooling system, a high pressure type blower was driven with the electricity from the $450 \mathrm{~W}$ solar cells, and pressurized air together with water at atmospheric pressure was supplied to the multi-fluid mixers in order to supply fine droplets in the house. Since high temperature in the house causes the loss of appetite and the poor growth of the baby pigs, the cooling in summer without commercial electricity is quite ecological.

The adsorptions of black smoke in the chimney from a furnace burning RPF (refuse paper \& plastic fuel) were tested by use of our spray system in a local boiler maker. Figs. 7a-7c show the pictures of the original boiler system with a RPF stock in front, RPF and a blower for air supply to the furnace. Originally, four cyclone separators were inserted in series between the furnace and the chimney outlet, but black smoke was still emitted as shown in Fig. 8a due to the incomplete combustion and to the poor cyclone separators performance.

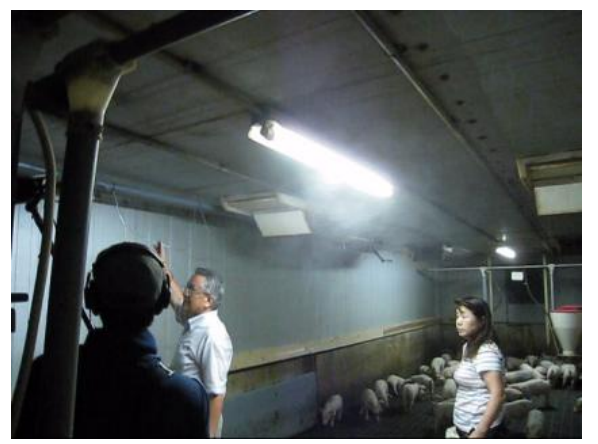

Fig. 5 Evaporative cooling of a baby pig in Kumamoto Prefecture broadcasted by TBS TV, Japan.

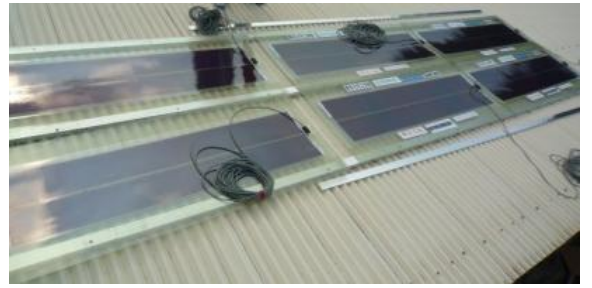

Fig. $6450 \mathrm{~W}$ solar cell on the roof of the pig house.

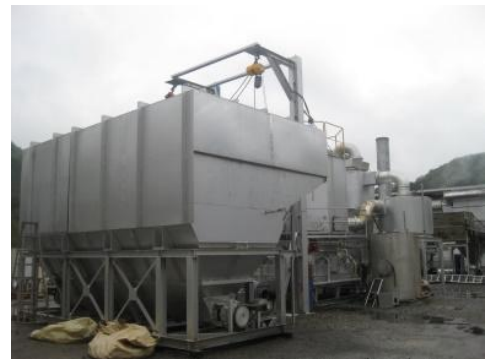

(a) Boiler system with RPF stock

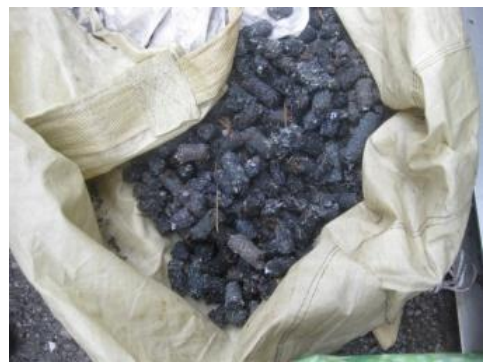

(b) RPF

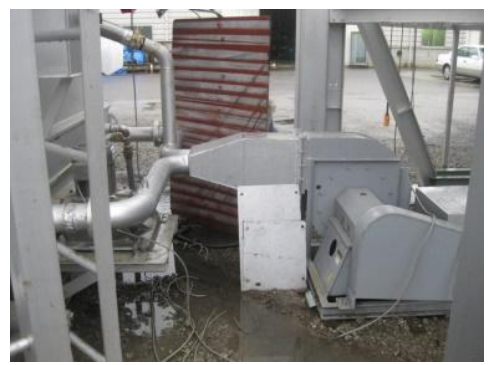

(c) Blower for air supply

Fig. 7 Original boiler systems in Oita Prefecture.

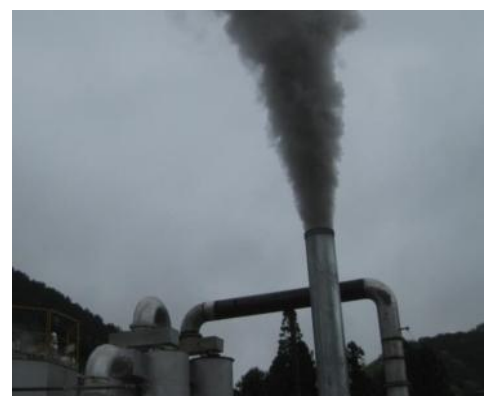

(a) Before revision

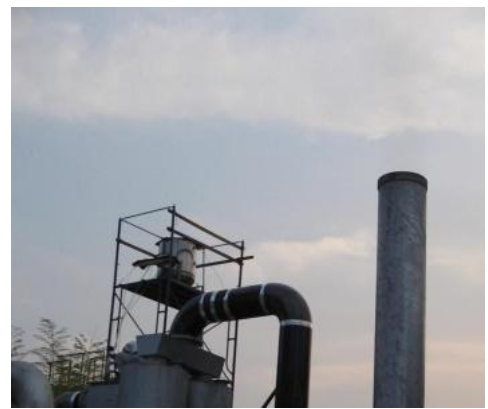

(b) After revision

Fig. 8 Black smoke removal by atomized droplets, etc. 
The boiler maker asked us to find an economical method to remove the black smoke. According to our advice, the maker took off three from the four separators in order to reduce the pressure drop from the furnace to the chimney outlet, and add one more blower in series at the inlet of the original blower in order to supply more air to the furnace for better combustion, and inserted our spray system into the smoke pass in order to adsorb finer smoke dust. As a result, the smoke could be cleaned up as shown in Fig. 8b.

\section{Comparison of Performance between Twin-fluid Type and Single-fluid Type}

\subsection{Spray Performance}

Fig. 9 compares the maximum mist flowrate, $Q_{L}$, among the twin-fluid $\mathrm{S}$ type, the twin-fluid MMA100 type and the single-fluid swirl type. The maximum means that the splay was conducted under the fully opened flow control valve in the water supply line. The abscissa is the power required to operate the atomizer, the pneumatic power, $L_{G}$, for the two kinds of twin-fluid types and the hydraulic power, $L_{L}$, for the single-fluid type. In the two twin-fluid types, $Q_{L}$ increases with $L_{G}$ because $Q_{L}$ increases with the air supply rate, $Q_{G}$. In the single-fluid type, $Q_{L}$ is proportional to $L_{L}{ }^{1 / 3}$. This is because $L_{L}$ is given as $Q_{L} \cdot P_{L 1}$, and $P_{L 1}$, being the same as the pressure loss through the atomizer, is proportional to $Q_{L}^{2}$.

If ten atomizers of the single-fluid type are used at the same time, $Q_{L}$ exceeds that for the twin-fluid $\mathrm{S}$ type, but the total of $L_{L}$ is one-hundredth lower than that for the twin-fluid $\mathrm{S}$ type. Thus, the single-fluid type has a merit in saving energy, but has a demerit of large liquid droplet as described in Fig. 10.

Fig. 10 compares droplet size distributions among the three atomizers, and Table 2 lists the operation conditions of $Q_{L}$ and $Q_{G}$, the mean and the Sauter mean droplet diameters. The operation condition for the single-fluid type corresponds to that shown in the maker's manual and that for the MMA100 to the maximum $Q_{L}$, and that the $\mathrm{S}$ type to nearly the same $Q_{L}$ as that in the single-fluid type. In the MMA100 type, $75 \%$ droplets are smaller than $20 \mu \mathrm{m}$, called "dry mist" and reported to be effective to the mitigation of heat island phenomena in megalopolis [11]. In the single-fluid type, $40 \%$ droplets are larger than $80 \mu \mathrm{m}$, which cannot suspend in air. In the twin-fluid S type, smaller droplets than $20 \mu \mathrm{m}$ are $45 \%$, and 20 to $40 \mu \mathrm{m}$ droplets are $40 \%$, while $20 \%$ for the MMA100 type. Since the fall velocity of droplet increases with its size, the smaller and the denser droplets seem effective to adsorb harmful gases. However, too small droplets like dry mist cannot adsorb them because they disappear due to evaporation.

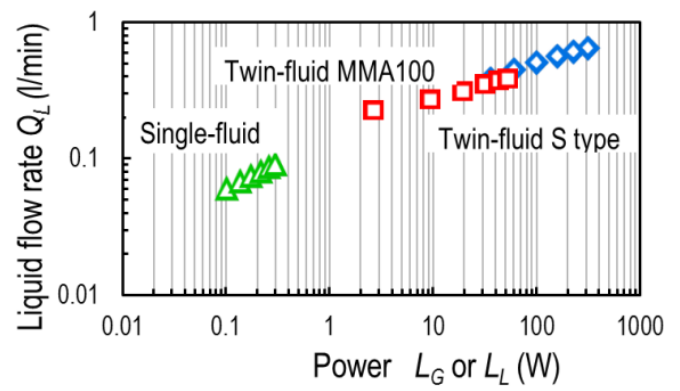

Fig. 9 Comparison of the maximum mist flow rate among twin-fluid $S$ and MMA100 types and the single-fluid type.

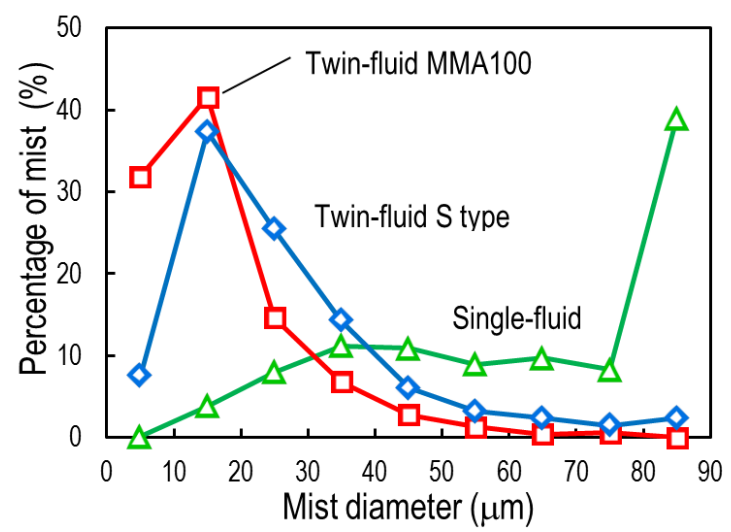

Fig. 10 Comparison of droplet size distribution among twin-fluid $S$ and MMA100 types and the single-fluid type.

Table 2 Operation conditions and drop sizes for three atomizers.

\begin{tabular}{lllll}
\hline Atomizers & $\begin{array}{l}Q_{L} \\
(1 / \mathrm{min})\end{array}$ & $\begin{array}{l}Q_{G} \\
(1 / \mathrm{min})\end{array}$ & $\begin{array}{l}d_{m} \\
(\mu \mathrm{m})\end{array}$ & $\begin{array}{l}d_{32} \\
(\mu \mathrm{m})\end{array}$ \\
\hline Single-fluid swirl type & 0.09 & 0 & 77 & 132 \\
Twin-fluid MMA100 & 0.38 & 27 & 17 & 35 \\
Twin-fluid S type & 0.10 & 170 & 27 & 86 \\
\hline
\end{tabular}




\section{$4.2 \mathrm{CO}_{2}$ Adsorption Performance with Mist}

Figs. 11a and $11 \mathrm{~b}$ show the pictures of mist room just after the stop of spay in the $\mathrm{CO}_{2}$ adsorption test respectively for the single-fluid swirl type and the twin-fluid $\mathrm{S}$ type. $Q_{L}$ for the twin-fluid $\mathrm{S}$ type was 0.10 $\mathrm{L} / \mathrm{min}$, while that for the single-fluid swirl type was $0.09 \mathrm{~L} / \mathrm{min}$, being the same as those in the test of Fig. 10. The picture for the single-fluid type is clearer than that for the twin-fluid $S$ type because larger droplets than $80 \mu \mathrm{m}$ cannot suspend in air because of higher fall velocity. In the twin-fluid type, however, droplets smaller than $40 \mu \mathrm{m}$ are about $85 \%$, and can float for a while if they were not evaporated, so the room becomes foggy as seen in Fig. 11b.

Fig. 12 shows time variations in $\mathrm{CO}_{2}$ concentration in air at the bottom of the mist room for the following four cases: three mists filled cases with the single-fluid swirl type, the twin-fluid MMA100 type and the twin-fluid $\mathrm{S}$ type, and no mist spray case. Shortly after the flow down of $\mathrm{CO}_{2}$ into the mist room, $\mathrm{CO}_{2}$ concentration detection was started at the bottom of the mist room. The $\mathrm{CO}_{2}$ concentration in air at $25 \mathrm{~s}$ from the start is the same as that outside of the room, i.e., about $470 \mathrm{ppm}$, because $\mathrm{CO}_{2}$ could not reach to the detectors. The concentration after $25 \mathrm{~s}$ rapidly increased with time, and took a maximum value at $150 \mathrm{~s}$ or after. The concentration in no mist spray case after the peak decreased gradually because of some leakage of $\mathrm{CO}_{2}$ to the outside.

The mass of $\mathrm{CO}_{2}$ adsorbed by the mists is known from the concentration difference between the mists filled case and the no mist spray case. The $\mathrm{CO}_{2}$ concentration difference from the no mist spray case for the twin-fluid S type is about $25 \%$ higher than that for the twin-fluid MMA100 type, and 50\% higher than that for the single-fluid swirl type. This means that the droplets of 20 to $40 \mathrm{~mm}$ in diameter are very effective to adsorb $\mathrm{CO}_{2}$.

From the $\mathrm{CO}_{2}$ concentration difference between 470 $\mathrm{ppm}$ at $25 \mathrm{~s}$ and the respective values at $525 \mathrm{~s}$, we can confirm that about $70 \%$ of $\mathrm{CO}_{2}$ in the mist room was

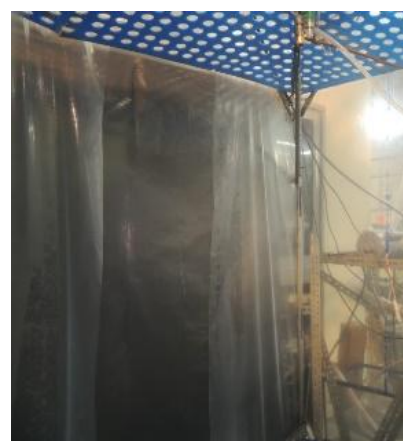

(a) Single-fluid swirl type

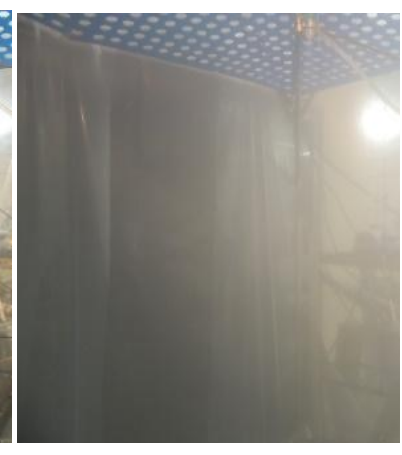

(b) Twin-fluid S type
Fig. 11 Pictures of mist room just after the stop of spay by the single-fluid type and the twin-fluid $S$ type.

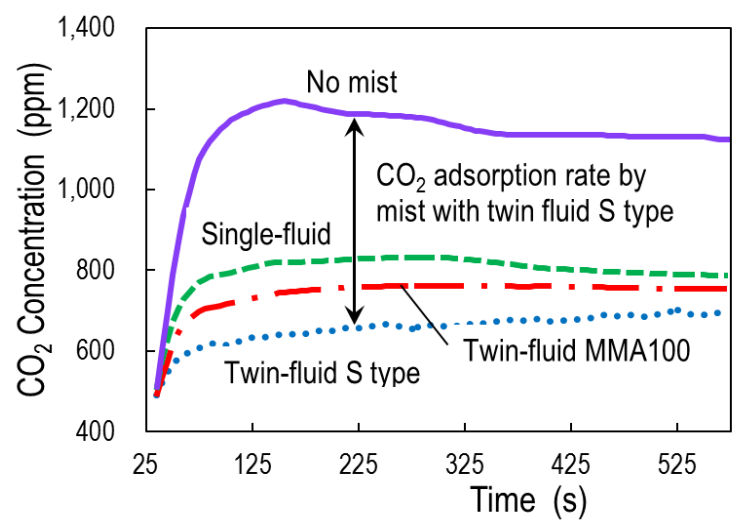

Fig. 12 Time variation in $\mathrm{CO}_{2}$ concentration in air at the bottom of mist room-Effects of mist generation method.

adsorbed by the mists in the twin-fluid $\mathrm{S}$ type case while about 55\% in the twin-fluid MMA type. Thus, the twin-fluid $\mathrm{S}$ type is superior to the commercial two atomizers in the $\mathrm{CO}_{2}$ adsorption by the mists under the above operation conditions.

\section{Conclusions}

Firstly, a twin-fluid water suction type atomizer invented by Sadatomi and Kawahara [2] was introduced together with its practical applications to date. Secondly, the performance of the twin-fluid atomizer with best performance, i.e., $\mathrm{S}$ type, was compared with those of the commercial twin-fluid MMA100 type and the single-fluid swirl type. From the comparison, the followings were clarified:

The ratio of the spray rate to the power required, $Q_{L} / L_{L}$ or $Q_{L} / L_{G}$, was much higher in the single-fluid type than the two kinds of twin-fluid types. Thus, the single-fluid type is superior in energy saving point of 
view. However, the droplets for the single-fluid type were bigger than those for the two twin-fluid types, and could not suspend in air.

The most droplets of the twin-fluid MMA100 type were smaller than $20 \mu \mathrm{m}$, and disappeared due to evaporation. 20 to $40 \mu \mathrm{m}$ droplets were $40 \%$ for the twin-fluid S type, and could suspend in air. The $\mathrm{CO}_{2}$ adsorption by mists was $70 \%$ in the twin-fluid $\mathrm{S}$ type while 55\% in the twin-fluid MMA100 type. Thus, the twin-fluid $S$ type is the best in the adsorption performance of harmful gases such as $\mathrm{CO}_{2}$.

\section{Acknowledgments}

The authors appreciate Dr. Yao J., Messrs. Sakurai E., Furusawa S., Tanaka K. and Kawano Y. very much for their cooperation in this series of studies, and financial supports from JSPS KAKENHI (Grant Number 26420117), Big Bio Co. and Kumamoto IDM Co.

\section{References}

[1] Lefebvre, A. H. 1989. Atomization and Sprays. London: Hemisphere Publishing.

[2] Sadatomi, M., and Kawahara, A. 2012. Fluids mixer and fluids mixing method. Japanese Patent, No. 5103625.

[3] Sadatomi, M., Kawahara, A., Fukamachi, K., Matsuyama, F., and Tanaka, N. 2010. "Development of a New Large-Flow-Rate and Efficient Mist Generator, and Its Application to Air Cooling in Greenhouses." Multiphase Science and Technology 22 (June): 79-93.

[4] Yao, J., Kawahara, A., Sadatomi, M., Sakurai, E., and Furusawa, S. 2013. "Expansion of Mist Jet Generated by a Special Twin-fluid Atomizer for $\mathrm{CO}_{2}$ Capture." WIT Transactions on Engineering Sciences 80 (July): 495-506.

[5] Yao, J., Tanaka, K., Kawahara, A., and Sadatomi, M. 2013. "Performance Evaluation of an Air Assisted Atomizer with Liquid Siphon." Journal of Applied Sciences 13 (November): 4985-93.

[6] Yao, J., Tanaka, K., Kawahara, A., and Sadatomi, M. 2014. "Geometrical Effects on Spray Performance of a Special Twin-fluid Atomizer without Water Power and Its $\mathrm{CO}_{2}$ Absorption Capacity." Japanese Journal of Multiphase Flow 27 (March): 511-20.

[7] Yao, J., Furusawa, S., Kawahara, A., and Sadatomi, M. 2014. "Influence of Some Geometrical Parameters on the Characteristics of Prefilming Twin-fluid Atomization." Transactions of the Canadian Society for Mechanical Engineering 38 (January): 391-404.

[8] Sadatomi, M., Tanaka, K., and Kawahara, A. 2015. "Comparison of Mist Generators between Twin-fluid Water Suction Type and Single-fluid Swirl Type." International Journal of Advancements in Mechanical and Aeronautical Engineering 2 (October): 200-4.

[9] Sadatomi, M., Kawahara, A., Matsuura, H., and Shikatani, S. 2012. "Micro-bubble Generation Rate and Bubble Dissolution Rate into Water by a Simple Multi-fluid Mixer with Orifice and Porous Tube." Experimental Thermal and Fluid Science 41 (September): 23-30.

[10] Sadatomi, M., Kawahara, A., Kurogawa, K., and Akasaki, T. 2015. "Purification of Deep Water in a Dam Lake Using Micro Bubbles and/or Eco-Bio-Ring." International Journal of Enviromental Science and Development 6 (June): 419-24.

[11] Ishii, T., Tsujimoto, M., Yoon, G., and Okumiya, M. 2009. "Cooling System with Water Mist Sprayers for Mitigation of Heat Island." Presented at the 7th International Conference on Urban Climate (July), Yokohama, Japan. 